\title{
INVESTIGATION OF COMBUSTION IN MINIATURISED COMBUSTOR FOR APPLICATION TO MICRO GAS TURBINES
}

\author{
J. Guidez, P. Roux, N. Poirson, E. Jourdanneau, \\ M. Orain, and F. Grisch
}

\begin{abstract}
Assessing the feasibility of combustion in miniaturised combustors (volume less than $1 \mathrm{~cm}^{3}$ ) is a key point for the development of micro gas turbines. This paper presents the results obtained in a combustion chamber operating with a hydrogen-air mixture. A stable combustion was obtained with an output power between 100 and $1200 \mathrm{~W}$, for air mass flow rate from 0.1 to $0.5 \mathrm{~g} / \mathrm{s}$, and equivalence ratio between 0.3 and 0.7. Experimental results were obtained using thermocouples to measure temperature of the burnt gases at the outlet of the combustor, and information on combustion efficiency and output power was derived. In addition, laser-based measurements were performed using spontaneous Raman spectroscopy and Rayleigh scattering to determine radial profiles of temperature and main species concentrations at the outlet of the combustor.
\end{abstract}

\section{NOMENCLATURE}

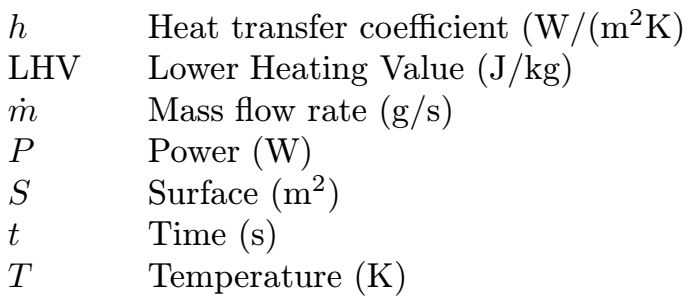

\section{Subsripts}

$\begin{array}{ll}a & \text { ambient } \\ c & \text { thermocouple (exhaust gas temperature) } \\ \text { ch } & \text { chemical }\end{array}$

This is an Open Access article distributed under the terms of the Creative Commons Attribution-Noncommercial License 3.0, which permits unrestricted use, distribution, and reproduction in any noncommercial medium, provided the original work is properly cited. 


$\begin{array}{ll}e & \text { external surface of the combustor } \\ g & \text { hot gases } \\ \text { net } & \text { net power } \\ \text { th } & \text { thermal } \\ w & \text { wall }\end{array}$

\section{Greek Symbols}

$\begin{array}{ll}\varepsilon & \text { Emissivity } \\ \eta & \text { Efficiency } \\ \Phi & \text { Equivalence ratio }=\left(\dot{m}_{\text {fuel }} / \dot{m}_{\text {air }}\right) / \text { stoichiometric ratio }\end{array}$

\section{INTRODUCTION}

In order to reduce the size and weight of power generators for small unmanned vehicles, several alternative systems to the currently used heavy batteries are investigated worldwide. Micro gas turbines are expected to offer the highest power density and, therefore, several research groups have initiated programs to develop ultra micro gas turbines, following the pioneering work of the MIT group [1].

At ONERA, a research program is ongoing [2], with the support of the Ministry of Defence (DGA/UM AERO), aimed at developing a demonstrator of a micro gas turbine engine delivering electrical power between 10 and $100 \mathrm{~W}$. The main application of this tiny engine is microdrone propulsion $(15 \mathrm{~cm}$ length and wingspan).

Due to the small volume of the engine (about $6 \mathrm{~cm}^{3}$ ), there are many problems to tackle: manufacturing of rotating and static parts, gas journal and thrust bearings (rotating speed up to 1 million rpm), combustion in a small volume, microelectromechanical converter, etc.

Taking into account these physical and technological challenges, ONERA has developed and tested different types of microcombustors. The first one is a small cylinder, $20 \mathrm{~mm}$ in diameter and $2.7 \mathrm{~mm}$ high, corresponding to a volume of $850 \mathrm{~mm}^{3}$. It is operated with an air-hydrogen mixture (air mass flow rate between 0.1 and $0.5 \mathrm{~g} / \mathrm{s}$ ). A very stable combustion has been obtained for a large range of equivalence ratios (0.3 to 0.7$)$. The wall temperature, measured by means of thermocouples and a two-color infrared pyrometer, does not exceed $1350 \mathrm{~K}$ at an equivalence ratio of 0.7 . Recording the temperature profile of the walls during transient sequences of heating or cooling and gas temperature at the outlet of the microcombustor (measured with a small thermocouple $-0.25 \mathrm{~mm}$ in diameter) allowed determining the overall efficiency of the microcombustor. The values obtained lie between 0.45 and 0.8 , depending on the equivalence 
ratio and mass flow rate. In order to better understand microcombustion phenomena, laser-based measurements using spontaneous Raman spectroscopy and Rayleigh scattering have been performed in addition to classical thermal measurements.

\section{CONSTRAINTS FOR THE MICROCOMBUSTORS}

Regardless of the final size expected for this micro gas turbine, scaling down a classical gas turbine combustion chamber obviously generates specific problems that have to be overcome [1-4]. In fact, low Reynolds number of the flow leads to poor mixing in the chamber between fuel and air, and also between cold and hot gases. Moreover, the reduced size of the combustion chamber decreases the gas residence time which becomes of the same order with the chemical reaction time. In the same way, external heat losses increase due to the high surface-to-volume ratio of the combustion chamber.

The potential performance of a micro gas turbine has been determined with the software developed at ONERA called "Hot button" $[2,5]$. Results pointed out the necessity to have a combustion power ranging from 300 to $1000 \mathrm{~W}$ in order to obtain a net power between 20 and $100 \mathrm{~W}$ after electrical conversion $[2]$.

Numerical calculations of the minimum reaction time of the air-hydrogen mixture in a perfectly stirred reactor have been carried out $[2,6,7]$, and a value around $0.1 \mathrm{~ms}$ was obtained (using $90 \%$ for both chemical and thermal efficiency). From these computations, it was possible to determine the minimum volume of the microcombustor necessary to achieve complete combustion. Using these results, a first chamber geometry was designed, manufactured, and tested. Characterization of the combustor was performed by classical temperature measurements (walls and gas) with thermocouples, and also by spontaneous Raman spectroscopy and Rayleigh scattering to evaluate the spatial profiles of the main species concentrations and temperature at the outlet of the chamber. The objective was to obtain complementary information on the chemical efficiency.

\section{EXPERIMENTAL SETUP}

A special laboratory has been built at ONERA - Palaiseau Centre and the first microcombustor has been tested [2]. This first combustor is presented in Fig. 1. It has a very simple geometry: a cylinder of $20 \mathrm{~mm}$ in diameter and $2.7 \mathrm{~mm}$ high, leading to a volume of $850 \mathrm{~mm}^{3}$. This volume has been determined for nominal values of combustion power $(500 \mathrm{~W})$, mass flow rate $(0.4 \mathrm{~g} / \mathrm{s})$, and Damköhler number (ratio between residence time and chemical reaction time $=10$ ). 


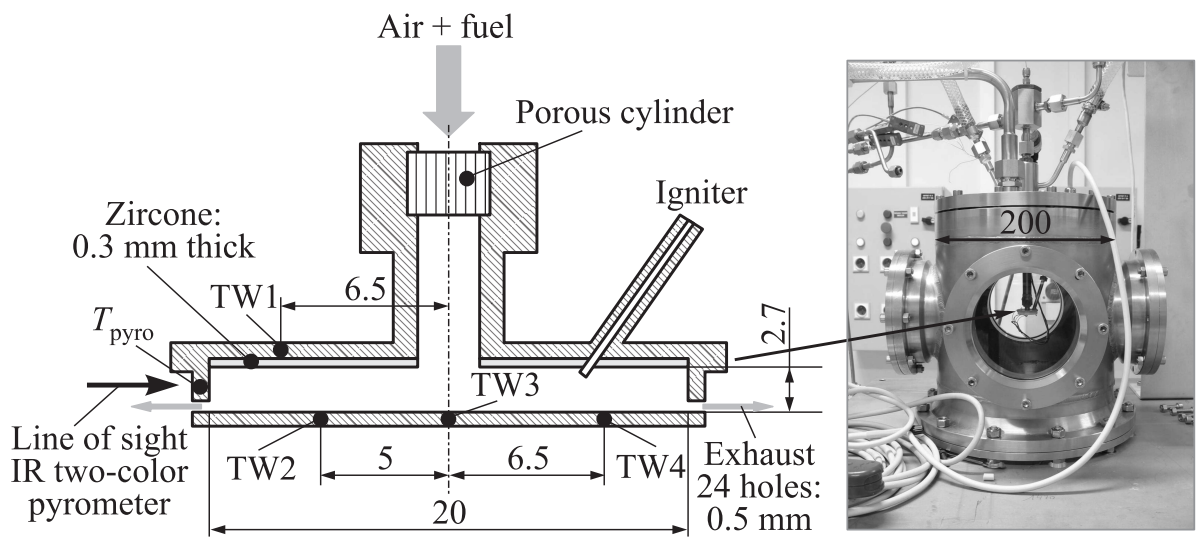

Figure 1 Cross-section of the first microcombustor and its position in the pressurised vessel. Dimensions are in millimeters

The air-hydrogen mixture (premixed case) is injected into the combustor through a water-cooled tube liner of $2 \mathrm{~mm}$ in diameter. A porous cylinder is added slightly upstream of the inlet of the actual combustor in order to eliminate possible flashback. A thin layer of zircon is deposited on the upper wall of the microcombustor to reduce the conductive heat transfer towards the water-cooled support. Combustion products are radially ejected through 24 holes of 0.5millimeter diameter. An electric discharge between the end of a tungsten wire (0.2 $\mathrm{mm}$ in diameter) and the wall of the microcombustor (in stainless steel) was used to ignite the air-hydrogen mixture. The igniter was manufactured by Thermocoax.

The combustor is equipped with 4 thermocouples $(0.5 \mathrm{~mm}$ in diameter for the sheath - type K) called TW1-TW4 in Fig. 1 to measure wall temperature at various locations. In addition, an infrared (IR) two-color pyrometer (wavelengths of 1.52 and $1.64 \mu \mathrm{m}$ ) is used to measure the overall temperature of the chamber. The microcombustor is placed in a pressurised vessel (1-5 bar) internally cooled by nitrogen, and the mixture of nitrogen and combustion products is ejected through an adjustable valve. The vessel is equipped with silica windows which allow optical measurements.

\section{THERMAL MEASUREMENTS}

The experimental conditions are summarised hereafter: air mass flow rate from 0.1 to $0.5 \mathrm{~g} / \mathrm{s}$, equivalence ratio between 0.3 and 0.7 , and inlet gas temperature of $300 \mathrm{~K}$. The microcombustor under firing operation is presented in Fig. 2 where air mass flow rate is $0.5 \mathrm{~g} / \mathrm{s}$ and equivalence ratio is 0.5 . 


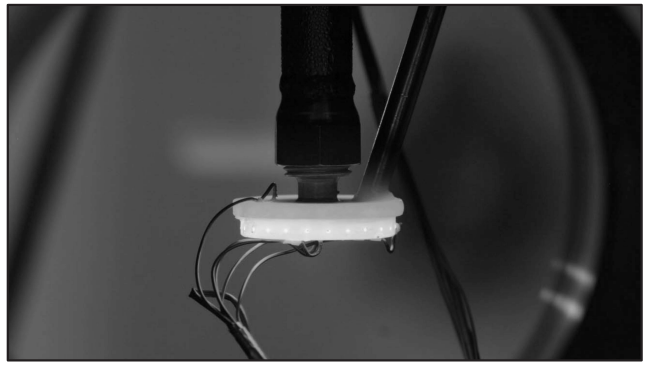

Figure 2 Microcombustor under operation

\subsection{Steady State Results}

Mean wall temperatures of the microcombustor, derived from the thermocouple measurements, are represented in Fig. 3 for different mass flow rates and equivalence ratios. As can be seen, the mean wall temperature increases from about 500 to $1150 \mathrm{~K}$ as equivalence ratio varies from 0.3 to 0.7 . The pressure in the combustion chamber is 2 bar.

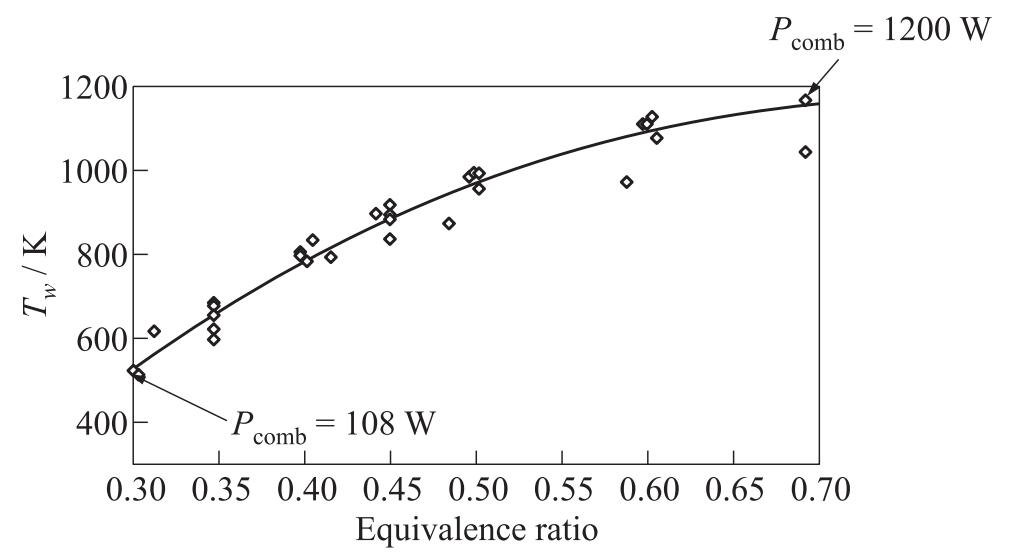

Figure 3 Mean wall temperature for the range of operating conditions

\subsection{Evaluation of the Combustor Efficiency}

The combustion power $\left(P_{\text {comb }}\right)$ lies between 108 and $1200 \mathrm{~W}$ and can be calculated as follows:

$$
P_{\mathrm{comb}}=\dot{m}_{\mathrm{H}_{2}} \mathrm{LHV}_{\mathrm{H}_{2}} \text {. }
$$


Combustion power requirement for ONERA's micro gas turbine engine [5] is of the order of $500 \mathrm{~W}$. This value is obtained in the middle of the experimental range presented in Fig. 3. For equivalence ratios less than 0.7, wall temperature is below the temperature limit of stainless steel (X8CrNi25-21/AISI310S).

Calculating the thermal efficiency of the microcombustor requires an evaluation of heat losses which can be obtained from the equation:

$$
P_{\mathrm{th}}=h_{e} S_{e}\left(T_{w}-T_{a}\right)+\varepsilon \sigma S_{e}\left(T_{w}^{4}-T_{a}^{4}\right) .
$$

The two unknown factors, the external heat transfer coefficient around the combustor $\left(h_{e}\right)$ and the emissivity $(\varepsilon)$ of the wall, can be determined using a method based on the wall temperature transients [8], after switching off air and hydrogen mass flows. Experiments were performed for different operating conditions. An external heat transfer coefficient of about $60 \mathrm{~W} /\left(\mathrm{m}^{2} \mathrm{~K}\right)$ and an emissivity of around 0.8 were inferred. The emissivity deduced from the two-color IR pyrometer was also nearly 0.8 . Heat losses can be now calculated using these values.

The net combustion power can be calculated with the equations [3]:

$$
P_{\text {net }}=P_{\mathrm{comb}}-P_{\mathrm{th}}-P_{\mathrm{ch}}=\eta_{\mathrm{overall}} P_{\mathrm{comb}}=\eta_{\mathrm{ch}} \eta_{\mathrm{th}} P_{\mathrm{comb}}
$$

where $P_{\text {ch }}$ (chemical losses) are due to the amount of unburnt fuel. Consequently, the overall efficiency of the microcombustor can be written as follows:

$$
\eta_{\text {overall }}=\eta_{\mathrm{ch}} \eta_{\mathrm{th}}=1-\frac{P_{\mathrm{th}}}{P_{\mathrm{comb}}}-\frac{P_{\mathrm{ch}}}{P_{\mathrm{comb}}}=\frac{P_{\mathrm{net}}}{P_{\mathrm{comb}}} .
$$

The chemical and the thermal efficiencies are defined as:

$$
\eta_{\mathrm{ch}}=\frac{P_{\mathrm{comb}}-P_{\mathrm{ch}}}{P_{\mathrm{comb}}} ; \quad \eta_{\mathrm{th}}=\frac{P_{\mathrm{net}}}{P_{\mathrm{comb}}-P_{\mathrm{ch}}}=\frac{P_{\mathrm{net}}}{\eta_{\mathrm{ch}} P_{\mathrm{comb}}} .
$$

Characterization of the overall efficiency of the microcombustor, and consequently the chemical efficiency, requires determining the gas temperature at the outlet of the chamber $[3,9]$. These measurements are obtained using a small thermocouple, $0.25 \mathrm{~mm}$ in diameter, which is located $1 \mathrm{~mm}$ downstream of the exhaust hole (Fig. 4a). Results obtained for the nominal air mass flow rate $0.4 \mathrm{~g} / \mathrm{s}$ are also presented in Fig. $4 b$. In this figure, the adiabatic gas temperature is represented with a solid line. The exit gas temperature measured with the thermocouple (dashed line in Fig. 4) must be corrected in order to eliminate the radiative losses and the conductive losses in the wires of the thermocouple. Additionally, a screen is placed around the thermocouple (see Fig. 4) in order to reduce the radiative transfer. The screen temperature is measured with the pyrometer. The values obtained for $T_{c}$ are represented with a dotted line in Fig. 4.

From the results obtained with the perfectly stirred reactor $[6,7]$, the different efficiencies can be calculated (Fig. 5). As can be seen, the overall efficiency 


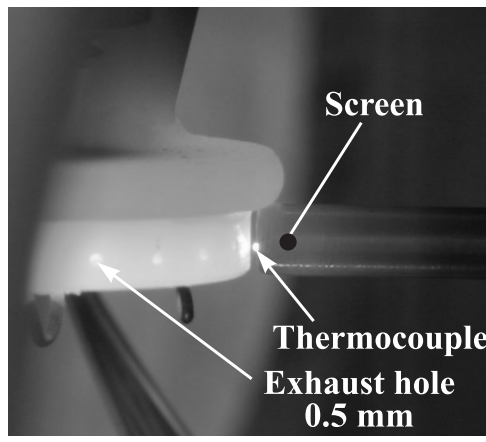

(a)

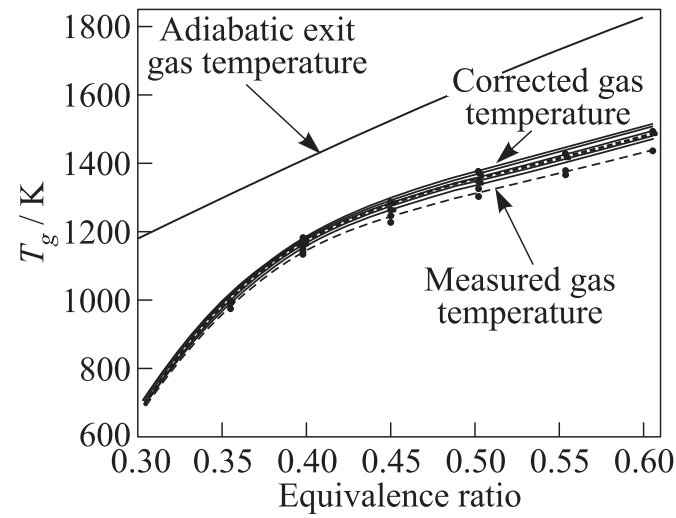

(b)

Figure 4 Exit gas temperature measured by thermocouple $(0.25 \mathrm{~mm}$ in diameter); mass flow rate is $0.4 \mathrm{~g} / \mathrm{s}$

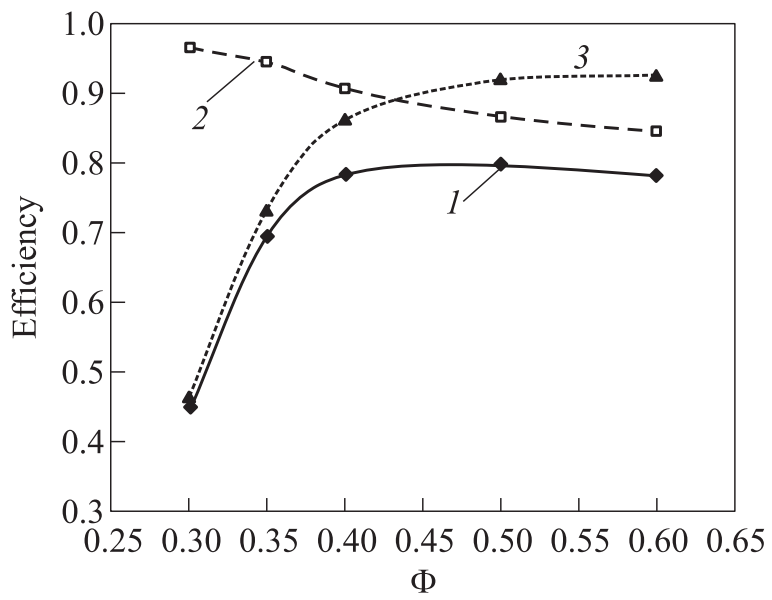

Figure 5 Overall (1), thermal (2), and chemical (3) efficiencies vs. equivalence ratio; air mass flow rate is $0.4 \mathrm{~g} / \mathrm{s}$

has a nearly constant value around 0.8 , for the equivalence ratio between 0.4 and 0.6. The thermal efficiency decreases slowly and its value clearly depends on the wall temperature. By contrast, the chemical efficiency increases sharply for equivalence ratios in the range $0.3-0.4$. The residence time of the flow in the microcombustor for the nominal mass flow rate, $0.4 \mathrm{~g} / \mathrm{s}$, is close to $1 \mathrm{~ms}$. 


\section{SPECIES CONCENTRATIONS AND TEMPERATURE MEASUREMENTS USING RAYLEIGH SCATTERING AND SPONTANEOUS RAMAN SPECTROSCOPY}

One-dimensional (1D) imaging Rayleigh scattering and spontaneous Raman spectroscopy have been applied for measuring temperature and major species concentration $\left(\mathrm{N}_{2}, \mathrm{O}_{2}, \mathrm{H}_{2} \mathrm{O}\right.$, and $\left.\mathrm{H}_{2}\right)$ at the outlet of a fired microcombustor operating with $\mathrm{H}_{2}$-air mixture (Fig. $6 a$ ). A frequency-tripled output of an $\mathrm{Nd}$ :YAG laser at $355 \mathrm{~nm}$, with a pulse energy of $70 \mathrm{~mJ}$ and $10 \mathrm{~Hz}$ repetition rate is focused $2 \mathrm{~mm}$ aside of the microcombustor, in an exhaust gas stream.

A half waveplate is mounted in front of the focusing lens, either to select Raman and Rayleigh signals, or background noise (blackbody radiation, species fluorescence, etc.). The scattered signal is collected by a first lens and then focused by a second lens onto the entrance slit of a grating spectrometer (Spex270M) connected to an intensified charge-coupled device (ICCD) camera $(576 \times 384$ pixel). A high-pass Schott filter (WG345) is used to set Rayleigh and Raman signals to similar amplitude. This experimental setup allows recording the spatial profile of Rayleigh and Raman signals along the laser beam over a distance of $4 \mathrm{~mm}$ across the jet of burnt gases. Analysis of these experimental data allows determining the expansion of the jet together with diffusion of different species in the surrounding atmosphere $\left(\mathrm{N}_{2}\right)$ and to quantify the combustion efficiency of the microcombustor. Typical signal evolution is shown in Fig. $6 b$ for an accumulation of 2000 single shots.

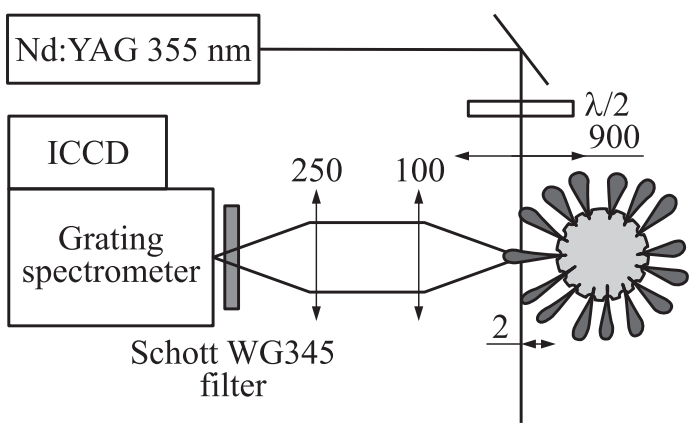

(a)

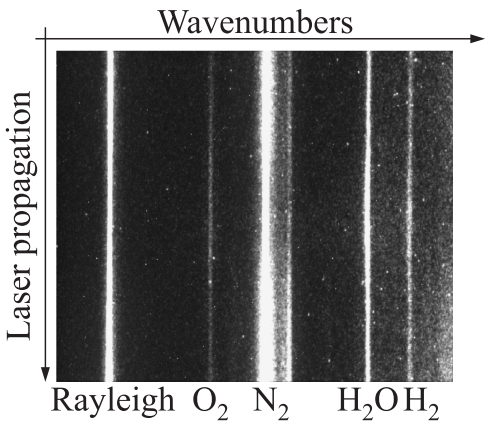

(b)

Figure 6 Experimental setup and spatial profile of Raman and Rayleigh signals across the jet of burnt gases for an air mass flow rate of $0.1 \mathrm{~g} / \mathrm{s}$ and equivalence ratio of 0.35 


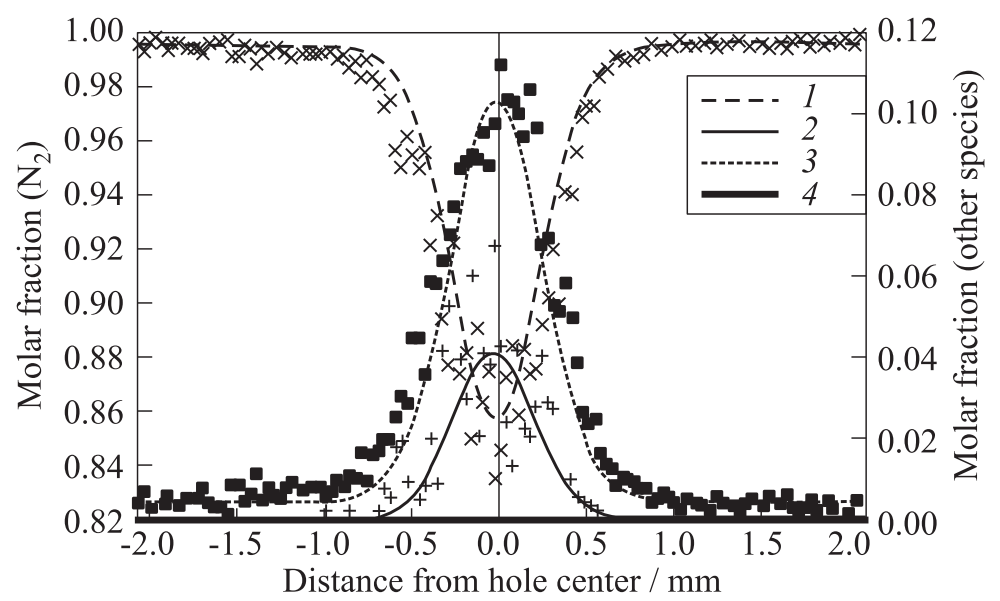

Figure 7 Radial profiles of molar fractions in the burnt gases jet (air mass flow rate is $0.1 \mathrm{~g} / \mathrm{s}$ and equivalence ratio is 0.4$): 1-\mathrm{N}_{2} ; 2-\mathrm{O}_{2} ; 3-\mathrm{H}_{2} \mathrm{O}$; and $4-\mathrm{H}_{2}$

Temperature information is obtained from the dependence of the Rayleigh scattering upon density number and species Rayleigh cross sections. Species concentrations are measured by analysing the shape of the Raman spectrum of different species. This method requires calibration curves for different temperatures and for each species. This calibration was performed in a flat $\mathrm{H}_{2}$-air flame for various equivalence ratios.

The main difficulty for optical measurements at the outlet of the microcombustor comes from the blackbody radiation of the chamber which increases dramatically with the equivalence ratio and air mass flow rate. This radiation interferes with Raman signals and may become prominent when the temperature of the combustor walls exceeds $1000 \mathrm{~K}$. As a result, it is difficult to properly quantify Raman signals for large equivalence ratios and air mass flow rates. Therefore, measurements were initially restricted to air mass flow rate of $0.1 \mathrm{~g} / \mathrm{s}$ and equivalence ratios between 0.3 and 0.7 .

The width of the burnt gases jet at a half-height of the profile is evaluated as $0.8 \mathrm{~mm}$ (Fig. 7) while the diameter of the outlet hole is $0.5 \mathrm{~mm}$, which indicates slight jet expansion and diffusion of species in the surroundings of the jet. With the present combustor, the velocity of the jet of burnt gases remains subsonic $(\sim 100 \mathrm{~m} / \mathrm{s})$ and the jet radial expansion is proportional to the distance from the outlet. Temperature was recorded $2 \mathrm{~mm}$ aside of the chamber exit and, therefore, the measured values are slightly lower than the actual values at the outlet because of plume cooling down due to jet expansion (although limited). Combustion processes in the chamber can be estimated as complete and, therefore, combustion efficiency is close to 1 ( 0.92 with the thermocouple, 

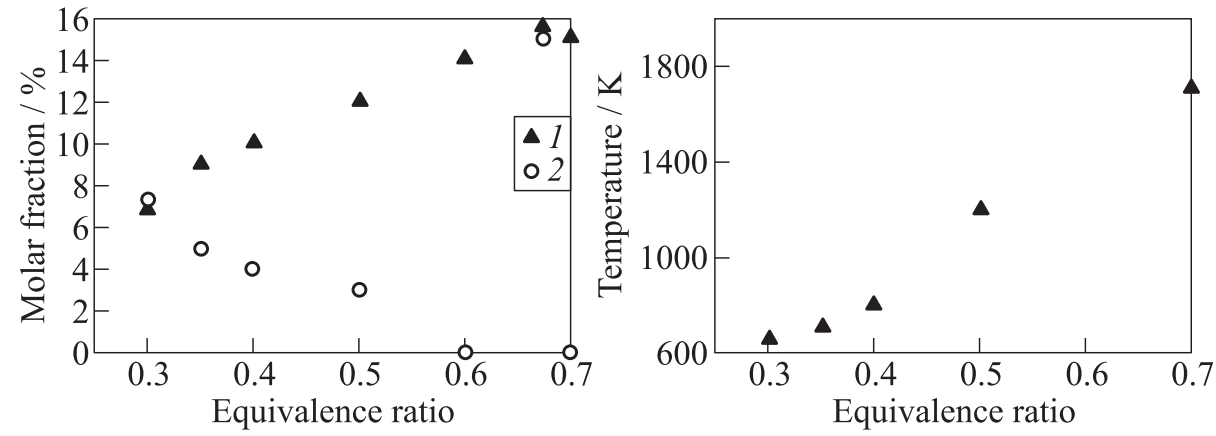

Figure 8 Molar fractions $\left(1-\mathrm{H}_{2} \mathrm{O}\right.$; and $\left.2-\mathrm{O}_{2}\right)$ and temperature vs. equivalence ratio for $0.1 \mathrm{~g} / \mathrm{s}$ air mass flow rate

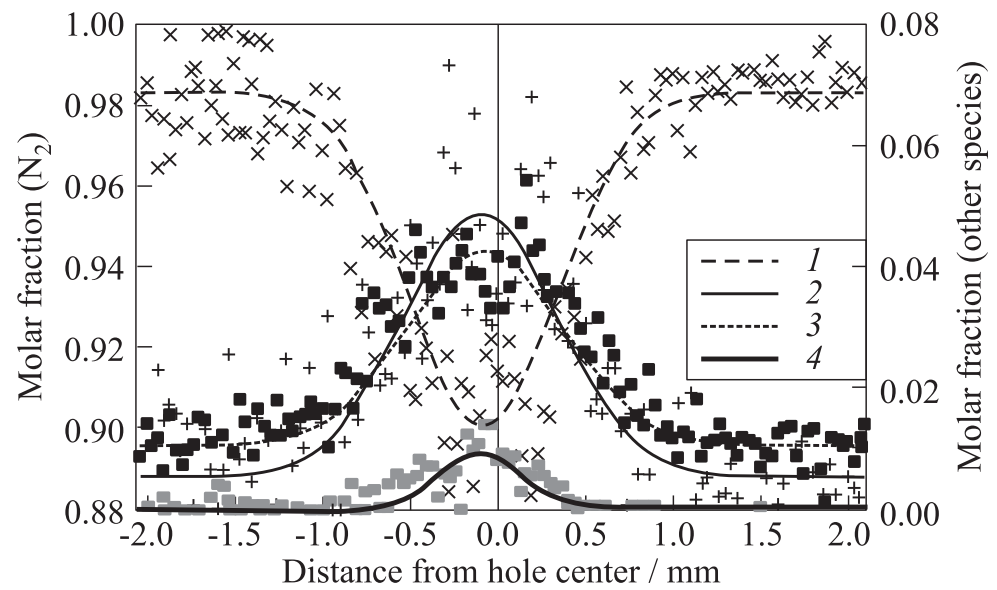

Figure 9 Radial profiles of molar fractions in the burnt gases jet (air mass flow rate is $0.4 \mathrm{~g} / \mathrm{s}$, equivalence ratio is 0.35 ): $1-\mathrm{N}_{2} ; 2-\mathrm{O}_{2} ; 3-\mathrm{H}_{2} \mathrm{O}$; and $4-\mathrm{H}_{2}$

see Fig. 5). Indeed, the ratio between oxygen and water molar fractions is very close to that obtained with numerical simulation of complete combustion, and no hydrogen residuals can be found in most cases. A summary of measurements with $0.1 \mathrm{~g} / \mathrm{s}$ air flow rate is represented in Fig. 8 .

With larger air mass flow rates, the problem of blackbody radiation interfering with Raman signals comes to effect. Therefore, the measurements performed with air mass flow rates of 0.4 and $0.5 \mathrm{~g} / \mathrm{s}$ were restricted to a low equivalence ratio (i.e., $\Phi<0.5$ ). As can be seen in Fig. 9, hydrogen residuals are observed with a typical molar fraction of $1 \%$ at $\Phi \sim 0.35$. This indicates that combustion 
is incomplete for this operating condition and combustion efficiency is reduced to about 0.87 in this case ( 0.72 with the thermocouple, see Fig. 5$)$. Such results can explain the oscillations observed for the temperature of the combustor walls with this operating condition. Indeed, due to the small combustor volume, flammability limits of hydrogen-air mixture can be reduced. As this condition is close to the lean extinction limit, combustion instabilities may appear in the chamber leading to incomplete combustion and variations of heat transfer to the walls. No hydrogen residuals were observed for a larger equivalence ratio.

\section{CONCLUDING REMARKS}

Experiments were performed with the first geometry of microcombustor operating with a hydrogen-air mixture for various air mass flow rates and equivalence ratio. An output power between 150 and $950 \mathrm{~W}$ was obtained, which is necessary to provide an electrical net power from 20 to $100 \mathrm{~W}$. Stable combustion occurs over a large range of air mass flow rates $(0.1$ to $0.5 \mathrm{~g} / \mathrm{s})$ and equivalence ratio ( 0.3 to 0.7$)$. Combustion efficiency is about 0.8 for equivalence ratios larger than 0.4. Rayleigh scattering and 1D spontaneous Raman spectroscopy

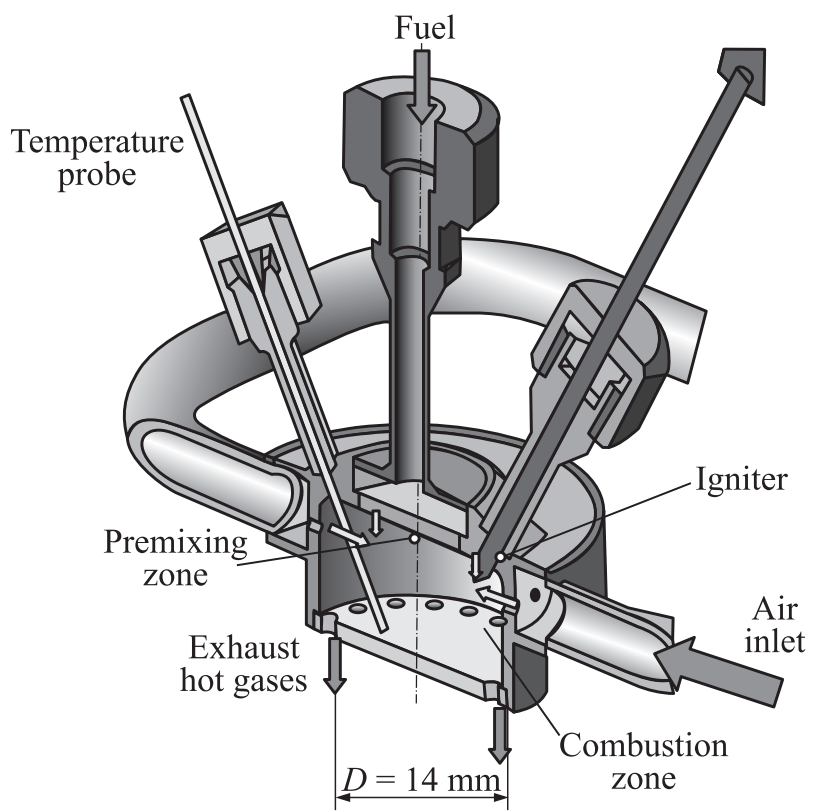

Figure 10 Design of a diffusion-type microcombustor 
were used for measuring radial profiles of temperature and main species concentrations at the outlet of the microcombustor. Three-dimensional numerical simulations were also carried out in order to compare with the experimental results.

The current test campaign will continue in the near future with a propane/air mixture to study the influence of fuel on the combustion efficiency. Furthermore, new combustion chambers of diffusion-type (Fig. 10) and a two-stage combustion chamber, directly linked to the new architecture of a micro gas turbine engine (ONERA patent, see paper No.394 - EUCASS 2007) will be tested and their performances will be compared.

\section{REFERENCES}

1. Epstein, A. H. 2003. Millimiter-scale, MEMS gas turbine engine. ASME Turbo Expo 2003 Proceedings.

2. Guidez, J., C. Dumand, T. Courvoisier, and M. Orain. 2005. Specific problems of micro-gas turbine for micro drones application. Munich, Germany. ISABE Paper No. 2005-1273.

3. Spadaccini, C. M., J. Lee, S. Lukachko, I. A. Waitz, A. Mehra, and X. Zhang. High power density silicon combustion systems for micro gas turbine engine. ASME Turbo Expo 2002 Proceedings.

4. Yuasa, S., K. Oshimi, and S. F. Wong. 2005. Specified problems and development of prototypes of ultra-micro combustor. Munich, Germany. ISABE Paper No. 20051272 .

5. Ribaud, Y. Internal heat mixing and external heat losses in an ultra micro turbine. International Gas Turbine Congress 2003 Proceedings. Tokyo. OS 109.

6. Dumand, C., and V. Sabel'nikov. 2005. The effects of micromixing on combustion extinction limits for micro combustor applications. 6th Symposium (International) on Engineering Turbulence Modeling and Measurements. Sardinia.

7. Dumand, C. 2005. Mélange et combustion dans les petits volumes: Application aux micro systèmes énergétiques. Ph.D. Thesis. Palaiseau, France: ONERA.

8. Cozzi, F., A. Coghe, and A. Olivani. 2006. Thermal and chemical efficiencies of a mesoscale combustor for propulsive or power generation systems. 3rd Conference (International) on Green Propellant for Space Propulsion, 9th Hydrogen Peroxide Propulsion Conference (International) Proceedings. Poitiers, France. ESA SP-635.

9. Shan, X. C., Z.F. Wang, Y.F. Jin, M. Wu, J. Hua, C.K. Wong, and R. Maeda. 2005. Studies on a micro combustor for gas turbine engines. J. Micromechanics Microengineering 15(9):S215-S221. 